\title{
EXPERIENCES OF STUDENTS, SERVICE DELIVERY ORGANISA- TIONS AND COMMUNITY MEMBERS OF SERVICE DELIVERY TO A DISADVANTAGED COMMUNITY BY SOCIAL WORK STUDENTS
}

\author{
Corinne Strydom, Minrie Greeff, Cornelia Wessels, \\ Engela van der Walt, Paul J Schutte
}

\section{INTERVIEWS WITH COMMUNITY MEMBERSPROBLEM STATEMENT}

This research is part of a more extensive research project in which the Departments of Social Work, Nursing and Communication collaborated to investigate the experiences of senior students' health care service delivery to a disadvantaged community, and to make recommendations to enhance quality multi-disciplinary health care service delivery to a disadvantaged community by the students of the University as part of their experiential learning.

This article will focus on the experience of the fourth-year social work students only. As part of their practical training in Social Work at the North-West University (Potchefstroom Campus), fourth-year students are required to render services to a disadvantaged community during a three-month internship at a service delivery organisation. For several years now the Department of Social Work has been offering services in various forms to a disadvantaged community through the students as part of their experiential learning. Experiential learning is an integral part of social work education. It is a collaborative effort between public and service delivery organisations and universities. Since student social workers work with individuals, families, groups and communities in real-life settings, they need to be intensively supervised by a supervisor from a delivery organisation and a lecturer from the University. This teaching and learning model in social work has evolved over many years and is internationally recognized as the most successful way of training a social worker over the course of a period of study (Association for South African Social Work Education Institutions (ASASWEI), 2006:4).

According to Wondmiku, Feleke and Tafete (2005:179), service learning is a valuable learning method. "Balancing the service and teaching objectives and maintaining the quality of both can be attained through careful twining of the objectives of both components". The service rendered by the students during experiential learning is especially directed at the disadvantaged community, and is in line with the focus specified in the White Paper for the Transformation of the Health System of South Africa (1997:13). The services rendered by the students included work at government and non-governmental organisations, home-based services to people living with HIV and AIDS, community projects such as planting eco-circle gardens, doing group work, assisting with parent guidance (Botswadi), empowering children, working with alcoholrelated problems, investigating child neglect and abuse, planning foster care, helping to obtain grants and handing out food parcels.

The arrangements to provide these services were made by the lecturers with people in the community whom they had identified as key people for the purposes of fulfilling the educational requirements, taking into consideration the areas where they thought the needs of the community were greatest. The Department of Social Work was virtually offering services based mainly on the requirements for experiential learning and needs of the students rather than on the needs of the disadvantaged community. These services were offered to the 
112

disadvantaged community in various forms and with the cooperation of various service delivery organisations.

However, over the years no evaluation was done on how the various partners (students, organisations and members) experienced this service delivery and its quality. The evaluation of the service delivery by social workers forms, and always did form, an integral part of their professional expertise (Bloom \& Fischer, 1982:476). Social workers can only "prove" their accountability by evaluating the effectiveness of their service delivery. Bloom and Fischer (1982:476) say the following with regard to service delivery and evaluation: "the fundamental objective of helping is to help, and the fundamental objective of evaluation is to improve that helping." Therefore the basic function of evaluation is, amongst other things, to ensure that the best professional service be delivered to the clients.

Lombard (2007:302) points out that social work educators play a vital role in preparing students for services to the poor and the vulnerable, since it has already been observed that many students indicate that they are unwilling to work within poverty-stricken contexts when they enter practice. It has thus become necessary to ensure that students' experiences during experiential learning match their expectations after completion of their training in order for them to cope in their professions.

The following research questions are derived from the introduction and problem statement:

- What are the experiences of senior social work students, service delivery organisations linked to this service delivery and community members to whom services were rendered regarding the quality of service delivery to a disadvantaged community?

- What could be done to enhance the quality of the service to a disadvantaged community rendered by social work students as part of their experiential learning?

\section{RESEARCH OBJECTIVES}

To be able to answer these questions, the following research objectives needed to be attained:

- To explore and describe the experiences of senior social work students, service delivery organisations linked to this service delivery and community members of a disadvantaged community during service delivery as part of the students' experiential learning;

- To make recommendations to enhance the quality of service to a disadvantaged community delivered by the social work students as part of their experiential learning.

\section{LITERATURE REVIEW}

Firstly, a few concepts need to be clarified. Secondly, a brief discussion of relevant theoretical perspectives will follow to place the research objectives in context. Thirdly, literature is indicated to support the findings from the focus groups and the interviews.

\section{Client}

The New Dictionary of Social Work (1995:10) defines client as an individual, a family, a group or a community that has either asked for, or sanctioned, social work services, or is expected to benefit from those services, or has entered into an agreement of cooperation with a social worker.

\section{Social Work}

Social work is defined as the applied science of helping people achieve an effective level of psychosocial functioning and effecting societal changes to enhance the wellbeing of all people 
(Barker, 1997:357). The Social Welfare Action Plan (Department of Social Welfare, 1998:121) states as its goal that appropriate social services should be provided to individuals and their families in communities who are unwell. The objective, in an attempt to achieve this goal, is to develop home-based, family-oriented and community care strategies in collaboration with other stakeholders.

\section{Needs of a disadvantaged community}

According to the New Dictionary of Social Work (1995:18), a disadvantaged community is one that has been disadvantaged educationally, economically or socially as a result of inferior education, inadequate infrastructure and lack of opportunities for growth and development.

People living in circumstances of poverty cannot contribute to maintaining their own health. They cannot purchase nutritional foodstuffs and this can lead to ill health, malnutrition and a high mortality rate (Bezuidenhout, 1998:161). A higher prevalence of disease is listed among lower-income groups, including tuberculosis, diarrhoea and fever, while higher rates of mental and physical disability are found among the poor (May, 1998:35; Uys \& Cameron, 2004:162). The infrastructure is not always there to address their health needs; for instance, there are few clinics in their area and there is no running water or sanitary facilities (Beytell, 2002:25).

More than one third of the South African population of 46 million is unemployed, with almost one third living below the poverty line (Statistics South Africa, 2006). Because of the high levels of unemployment and illiteracy in disadvantaged communities, they are to a large extent dependent on social grants. Currently the number of beneficiaries of grants and pensions is 12 million persons (South Africa, 2007:4). Because of lack of money, their houses are inadequate, leak rain and dust, have weak foundations and are too small for the number of people living in them (Bezuidenhout, 1998:161; Swanepoel \& De Beer, 2006:4). Overcrowding can lead to a lack of privacy, irritation with one another and children who tend to wander (Bezuidenhout \& Joubert, 2003:59). There are almost no appliances in the houses such as stoves or fridges, and there is also a shortage of clothes and furniture in these communities. The social worker is the person people turn to for material assistance, be it for the application of grants or for food parcels.

Because of the low level of education the members lack basic knowledge and skills, and the social worker should develop programmes in which they could be trained in various skills. Income-generation and job-creation projects are some of the ways in which poverty issues could be addressed (Gathiram, 2005:127).

There is a high incidence of HIV/AIDS in disadvantaged communities (Evian, 2003:21; Tladi, 2006:371; Uys \& Cameron, 2004:162). According to Barnett and Whiteside (2006:296), poverty assists the spread of HIV and AIDS and forces people into poverty, or makes it harder for them to escape from it. The social work profession needs to take responsibility for psychosocial services, and education and training regarding HIV and AIDS. Social workers' specialised knowledge, skills and training means that they are the most suitable professionals to deal with all psychosocial issues regarding HIV and AIDS (Spies, 2007:291). AIDS orphans have to be placed in foster care, which requires extensive administrative work. There is also the problem of child-headed families which requires attention (Evian, 2003:21; Schenck, 2004:159; Uys \& Cameron, 2004:163).

Another issue the members from the disadvantaged community bring to the attention of the social workers centres on family and marital problems. These include family conflict, domestic violence, and alcohol and drug abuse (Schenck, 2004:161). Economic deprivation increases the 
level of stress experienced by the parent and this, in turn, may negatively affect the parent's affective relationship with the child and his/her quality of parenting (Bezuidenhout \& Joubert, 2003:58). Frederick and Goddard (2007:335) remark that child neglect is associated with poverty. In order for changes to occur in the circumstances of a disadvantaged community, social workers should empower the community and provide community-based services (Strydom, 2008:68).

\section{Qualities of service providers}

Students should have particular personality traits in order to meet the needs of the people and to render effective services. In a study conducted in Natal respondents felt that service providers should be caring and tolerant, down to earth and able to understand people (Simpson, 2003:159). It is important for the service providers working in disadvantaged communities to adopt a humble attitude, as they begin the process of trying to understand what it is like for people to live in disadvantaged areas. All people value respect and want to be treated as worthy individuals (Simpson, 2003:159).

It is important for students to be able to communicate well with everyone. There is a need for the students to establish rapport between them and the members, because with such rapport any form of communication is much easier and meaningful (Swanepoel \& De Beer, 2006:150). According to Simpson (2003:158), the experience of being accepted and understood makes for successful helping. She adds that good service providers are real people with whom clients can identify. Service providers should be culturally competent. According to Sevel, Cummins and Madrigal (1999:42), this means that they need to acquire knowledge of a variety of cultural dimensions such as attitudes, values, customs, community patterns and spirituality that define particular cultures in order to respond effectively to the needs of diverse populations. Skills such as empathic responses, genuineness and clarification are helpful in establishing therapeutic relationships across all cultural lines (Sevel et al., 1999:44). The respondents in a study conducted in Natal mentioned that race was not a problem and that they had no preference in this respect. They did, however, feel that it would be more helpful for the service provider to be able to speak the local language (Simpson, 2003:158).

\section{Motivation for service providers}

In a study conducted by Bozalek, Henderson, Lambert, Collins and Green (2007:35) service providers said that it helped when the clients were grateful for work done. This motivated them to continue working and helping others. It also helped them when they could see that the client was willing to make an effort to change. It was important to believe in the resilience of people, in their ability to bounce back, their survival skills and ability to solve their own problems. Making a difference in the community and being valued by clients were other important motivations. Service providers said that they like working with people and listening to their stories (Bozalek et al., 2007:35).

\section{METHODOLOGY}

\section{Protection of human subjects}

The research protocol was approved by the Ethics Committee of the University. Permission to conduct the study was also obtained from the provincial Department of Health. Respondents were provided with information on the background of the study and informed that participation was voluntary and that they could withdraw from participation at any stage of the investigation. Respondents were also assured of confidentiality of information obtained (Neuman, 2000:283- 
284). Following this explanation, respondents each signed a written consent form. Informed consent is generally regarded as the main mechanism for providing protection for the rights and welfare of the individual (Boulton \& Parker, 2007:2188-2189).

Small tokens of appreciation or food parcels as applicable were provided to respondents.

\section{Research design}

A qualitative design was used to explore and describe (Mouton \& Marais, 1996:45) the experiences of the afore-mentioned role players. Focus group discussions (Greeff, 2005:299; Neuman, 2000:274) were conducted with the senior social work students as well as the service delivery organisations, while unstructured one-on-one interviews (Greeff, 2005:292) were conducted with the disadvantaged community members.

\section{Settings}

The focus group with the social work students and the focus group with the service delivery organisations were conducted at the Department of Social Work. The individual interviews with community members took place at the office of one of the service delivery organisations.

\section{Population}

Three populations were involved. The first population consisted of fourth-year social work students, seeing that this year group had the most experience of experiential learning in the disadvantaged community. The second population consisted of members from government and non-government delivery organisations. The last population consisted of disadvantaged community members who had received services from the students.

\section{Sampling}

Non-probable purposive voluntary sampling was used, because the researchers intended to sample people who were involved in service delivery of the students (Maree \& Pietersen, 2007:10). In other words, the criteria for the selection of this sample were:

- Fourth-year social work students who had just completed their internship and had delivered services to a disadvantaged community. Eight students were selected to be part of a focus group;

- Service delivery organisations where these students had been placed. Four social workers from the provincial hospital, correctional services, the child welfare society and the Dutch Reformed Church's welfare organisation participated in a focus group;

- Members of the disadvantaged community who had received services from these students during experiential learning. The social workers conducted personal interviews with three community members.

In other words, two focus groups and three interviews were conducted with a total of fifteen respondents. The size of the sample was small, but adequate, because it was a homogeneous population (Maree \& Pietersen, 2007:10). Three sets of respondents were involved and the data became saturated. This project was also part of a more extensive research project in which the experiences of senior nursing students in a disadvantaged community were similarly explored. In so doing, more participants were involved. 


\section{Data collection}

According to Greeff (2005:299), focus groups are a means to better understand how people feel or think about an issue, product or service. All focus groups and interviews were conducted in Afrikaans and/or English and audio-taped.

In the case of the focus groups all the interview schedules were evaluated by the research team in advance and referred to experts for comment. The estimated time of an hour for the group was communicated to them. During the focus groups, communication techniques (Okun, 1992:70-71) and group facilitation strategies (Greeff, 2005:307) were used to ensure participation. Communication techniques (Okun, 1992:70-71) facilitated the interviews. The various focus groups were opened with the following questions:

Social work students:

- How did you experience service delivery to the disadvantaged community?

- How did you experience the communication with the community?

- How did you experience the communication with the lecturers who made the arrangements for service delivery?

- What would enhance the quality of service delivery to the disadvantaged community?

Service delivery organisations:

They were asked similar questions focusing on their experiences of the service delivered by the students.

Community members:

- How did you experience the service delivery to you by the students?

- How did you experience the communication with the students?

- How do you think the quality of this service delivery by students could be enhanced?

Field notes were taken at the end of each group or interview, focusing on personal, observational and methodological notes (Polit \& Hungler, 1997:307; Talbot, 1995:478).

\section{Data analysis}

All the focus groups and interviews were transcribed verbatim and analysed using the open coding technique of Tesch (Creswell, 2003:153-155) to identify themes and sub-themes. The data were coded by one team member of the research team and verified by the rest of the team. Discrepancies were discussed until unambiguous themes and sub-themes were agreed upon and consensus was reached.

\section{Trustworthiness}

Rigor was ensured in this research to assess the trustworthiness of the qualitative data by using Guba's model (Krefting, 1991:214). The following criteria were used:

- Truth value. Triangulation occurred when focus groups and interviews were conducted by experienced researchers; field notes were taken; the theory reviewed; and a trial run was undertaken of the interview schedule. The researchers were known in the community as part of service delivery and there was a relationship of trust;

- Applicability. Communication and focus group techniques increased credibility through reframing, repeating and expanding. Detailed information regarding the context, respondents and methodology allows other researchers to transfer the findings; 
- Consistency. Data were analysed by all the researchers and discussions were held to reach consensus regarding themes and sub-themes.

\section{FINDINGS}

The findings of the research will be presented next. The findings of the three groups mostly confirmed what the others had said and occasionally added more richness or detail. Some verbal quotes from the various groups are reflected to enrich the findings.

TABLE 1

\section{THEMES AND SUB-THEMES}

\begin{tabular}{|c|c|}
\hline Theme & Sub-theme \\
\hline $\begin{array}{l}\text { Experiences of students, organisations and members of the } \\
\text { community regarding service delivery. }\end{array}$ & $\begin{array}{ll}\text { - } & \text { Initial contact } \\
\text { - } & \text { Welcomed in homes } \\
\text { - } & \text { Needs of community } \\
\text { - } & \text { Interventions } \\
\text { - } & \text { Respect } \\
\text { - } & \text { Culture differences } \\
\text { - } & \text { Type of services } \\
\text { - } & \text { Rewarding experience } \\
\text { - } & \text { Changes of students } \\
\end{array}$ \\
\hline $\begin{array}{l}\text { Experience of students, organisations and members } \\
\text { regarding communication with one another }\end{array}$ & - Language barrier \\
\hline Experiences of students and organisations with lecturers & $\begin{array}{ll}\text { - } & \text { Arrangements } \\
\text { - } & \text { Relationship between lecturers and } \\
& \text { supervisors } \\
\end{array}$ \\
\hline $\begin{array}{l}\text { Recommendations of students, organisations and members } \\
\text { to enhance service delivery }\end{array}$ & $\begin{array}{ll}\text { - } & \text { Better preparation } \\
\text { - } & \text { Cultural competence } \\
\text { - } & \text { Group work } \\
\text { - } & \text { Well-structured arrangements } \\
\text { - } & \text { Less changing of students }\end{array}$ \\
\hline
\end{tabular}

\section{EXPERIENCES OF STUDENTS, SERVICE DELIVERY ORGANISATIONS AND MEMBERS OF THE DISADVANTAGED COMMUNITY REGARDING SERVICE DELIVERY BY STUDENTS}

\section{Initial contact}

Both students and organisations described the initial contact with the disadvantaged community as strange and difficult, as it was so different from their known world. As a student said: "I was so frightened I did not want to look out of the window when we travelled in the community." A verbal quote from the organisation: "It was a shock to them." "They sometimes cannot handle it." "For some students it was the first time they ventured into another community different from theirs." "They see it as a new discovery as their worlds are so different". The difference in body boundaries is a specific issue and creates initial fear as a result of not understanding the closeness of the contact made by people from the community. "They come so close. I did not understand." However, they soon adjusted to this new experience. 


\section{Welcomed in homes}

The clients welcomed them into their homes and felt positive towards them. "I am glad when they come". They also see it as bridging the gap between the two communities, if the students visit their homes. The community gets to know the students.

\section{Needs of community}

The students experienced the needs of the community as vast and basic. They are shocked by how little the community has. "This was an eye opener. People's needs are very, very different. But if you find out what they need...it is so small and basic what you give." "We take so much for granted." "Just the little knowledge you share helps." "The information we give can be transferred to the rest of the community."

\section{Interventions}

The students would do basic interventions and provide basic health and social education, which the clients appreciated. "They taught us how to care for our children and how to treat them. We learned a lot." "They helped us to obtain grants". They mention that the need is so huge that they appreciate the help the student provides. "There are so many people with problems in the area."

The students wished to go in and change the community, but soon realized that they had to hear what the clients' needs were and not impose their preconceived ideas. "I thought I wanted to change the whole place....and then I realized they don't have those needs." The often limited insight of the client is very difficult to handle. "The limited insight made it difficult for me."

\section{Respect}

The student's perceptions are that the community looks up to them and respects them. The students perceived a possible stigma attached to making use of the social workers and that they were occasionally misused. "It is as though there is a stigma to use the social worker."

Feeling respected was important for the community and they wanted to know that they were accepted by the students as equals. "If you respect them, they experience you as positive. "They value the services offered."

The organisations perceived the community's experiences of the students as positive, because the students were truly interested, supportive and committed. "Someone playing with the children ... the other doing the garden." "They provide services."

The community felt comfortable with the students and did not feel shy. "It is happiness." Students are seen to be prepared to share their time with clients and to be available. "They feel today somebody is coming to heal their wounds". "There are at least people who care for me."

\section{Cultural differences}

The students experienced cultural differences, but felt that they could easily overcome these by acknowledging the differences with respect. "You come from a different culture, but you learn and see what is important during interaction." "They are sensitive about their culture and if they see you respect it, they will be very pleased." The theory did prepare them, to some extent, for what to expect of the culture, but they were not prepared enough to make initial interpersonal contact. They explain this as follows: "I do not know how they wanted to be greeted - what is important to them during interaction." Making the change to the client's level was seen as important. "It is a mind switch to come to their level." 
If the students become part of the culture, for example, by eating with them, there was a still stronger acceptance of the student. "I ate vetkoek they made and they were very surprised, but it brought me closer to them."

\section{Types of services}

The organisation experienced that the students displayed genuine interest in the community. "They are so involved with the client." "They will work with any type of client no matter what." "They use their initiative."

The organisation observed a sincere sympathy among the students for the hardships of the community. "They were feeling sorry like when they enter the shack with nothing but maybe a bed and an old person lying there with nobody." "So you see they care. They don't just do it for their study." The clients confirmed this observation of the organisation and pointed out that they experienced the students as empathic and caring by being loving, kind and friendly. "They give love and play with our kids." "They are friendly and they talk nicely to us."

The clients experienced the students as being available to listen to their stories and spend time with them. "They are beautiful and you open your heart to them." "We can just sit and talk." "She is so sweet. She had time to listen to us. She understood what I told her."

Both the organisation and the clients mentioned the hope that the students bring to the community. Comments from the organisation included: "They are so positive." "They are witty and joke with the clients." Comments from the clients: "When the students got here they helped a lot. It seemed as though we were losing hope. They uplifted our spirits." The clients mention that when they were losing hope, the students' presence pulled them through. The students also prayed for them and read from the Bible.

The organisations also felt supported by the students. "They are interested and they want to know how we are able to handle all these people." The students also provided much needed additional services that the organisations could not provide or initiate because of time constraints. "They help with food parcels, small administrative tasks, start new projects and do group work."

\section{Rewarding experience}

The students initially questioned the helpfulness of what they were doing, but became more aware of their value to the community as the discussions progressed. They found that giving a little of themselves meant a great deal to the client. "I think we do not always realise the difference we make. You feel so small and helpless until the client says thank you and you realize it was help." "Just that little I give...help them along." The students felt that so much could still be done.

The placement in the community became a very rich and rewarding experience for the students. They felt enriched, gained a lot and saw life differently. "A friendship or a relationship with someone...it is a dimension where the student has worth." "I gained more than I gave." "We have received so much from them in the end."

\section{Changes of students}

The clients found the changing of students less easy to cope with. They had to cope with various students. The contact the students had with the clients varied from one to a few contacts, making relationships difficult. "It is not one person coming. They change all the time." However, this did not prevent them from talking to the student or wanting them to come 
back. "We must sit and talk and that makes us feel better." "She is gone now and I am so heartsore and sorry. We get used to them." Some students made follow-up calls by phone, which was appreciated.

Experiences of students, service delivery organisations and members of the disadvantaged community regarding communication with one another

\section{Language barrier}

Both students and organisations saw language as a problem, whereas the clients did not see it as a problem. The students experienced language as a huge barrier in providing care. They do not always understand black people's communication, which could be frustrating to some. At the same time they have to practise new skills while in the community. The language also limited meaningful contact and interaction. "They know we will not understand them and then keep quiet." It also limited their ability to do all they wanted to for the patient. "Certain things you want to tell them...now you can't." An interpreter was of value, but it did extend the time of communication. "Someone has to talk on your behalf, but you don't know that it truly is what you wanted to communicate." They had a need to be able to communicate with the client in their own language. "Groups tend to be easier as the group members help one another if they do not understand." They did, however, find that clients would share information if you were prepared to listen. "If you listen, they are more open to share information."

The organisations confirmed language as a possible obstacle during service delivery by students. "Language is our biggest problem." They mentioned that not being able to speak Setswana is difficult and painful for the students at times, but that they make a concerted effort to speak at least some of the Tswana words or make use of an interpreter. "An interpreter is not always the most effective option, because when a client trusts the student, he wants to communicate directly and not through the interpreter." The student's personality and emotional maturity does play an important role in overcoming the language problem. "Some find it easier than others."

The clients, on the other hand, felt that language was not really such a barrier. If empathy and respect were present, it became possible to transcend the language barrier. "We did not struggle with language." "We would talk to one another nicely." "They are friendly people and we talk to them." The clients stated that somehow they found a way to overcome the language barrier between them and the students.

Experiences of students and service delivery organisations with lecturers who made the arrangements

\section{Arrangements}

The students experienced the communication with the lecturer making the arrangements for service delivery as mostly effective. "If the expectations were clear and you clearly knew why you went, it was positive." "To at least feel welcome at the organisation was important." Students expressed the need to see lecturers more often.

\section{Relationship between lecturers and supervisors}

It seems that the experiences of the organisation with lecturers were also mostly positive. The organisations appreciated well-planned and structured arrangements provided well in advance. "It is a set structure." "In the most cases we are well informed." They appreciated it if they knew what the expectations were for these students and what support was expected. "I think we and the University have a good relationship." They experienced the students as well prepared, 
making the placement more meaningful. The organisations felt that they would like to see the lecturers on a regular basis.

Recommendations of students, service delivery organisations and members of the disadvantaged community to enhance service delivery

\section{Better preparation}

Students should be prepared for and informed about the differing context they will be facing, either by students previously exposed to the situation, or by the supervisors who are working in the community. They should be prepared for the harsh reality, problems and cultural beliefs and customs before their first encounter. Students who participate for the first time should also visit the relevant sites before they actually become involved in the community.

\section{Cultural competence}

Lectures in intercultural communication would help overcome the cultural barrier. Ideally these aspects should form part of the curriculum. Students should be helped to work through any preconceived and prejudged thoughts and feelings before they start working in a disadvantaged community. Any form of guidance could enhance the student's confidence and ability to communicate effectively. The lecturers or organisation should also prepare the students when the sessions shift from the office of the organisation to the homes or informal settlements where the people are living. A much more co-ordinated process should be introduced to ensure quality service delivery to a disadvantaged community.

With regard to different languages, lectures in the relevant language of the community would help to overcome the language barrier. The problem is that the necessary intercultural competencies, which involve more than just language proficiency, take time to acquire, but even a spoken knowledge of the language would be of great assistance. At the same time students must be informed about and prepared to first earn the trust of the patient by listening well and building a relationship before they respond by saying and doing what would be congruent with the client's needs.

\section{Group work}

More group work with the clients should be done as group members could help one another to understand what the student is saying. When the student leaves at the end of the placement, group members will at least have one another.

\section{Well-structured arrangements}

Very well-structured practical arrangements should be made well in advance and communicated to the relevant parties. The problem is that the relationship between the student and the supervisor can be jeopardised, if communication between the two organising role players is inadequate or not properly done, while the "innocent" students would be the role players to suffer. Lecturers should visit the organisation on a regular basis in order to cosupervise the student. It is recommended that the supervisors who are involved in field placement should attend a one-day workshop at the University at the beginning of the year. It will be presented free of charge and they will receive certificates. The workshop will inform them on all the aspects related to student placement and supervision. Supervisors should also be invited to a function at the end of the year at the Department of Social Work. During this function students will report back on their field placement, and the supervisors and lecturers will have time to evaluate the placement. 


\section{Less changing of students}

The already good relationship between the students and the clients can be enhanced, if it were possible for the same student to help the same clients over a longer period of time. The relationship could grow in depth and the quality of the help would improve from the longer involvement.

\section{CONCLUSIONS}

Although there are smaller differences in the experiences of the three groups, it is interesting to see how many similarities there are. Students as well as organisations mentioned the initial shock experienced by students when they were confronted with the disadvantaged community for the first time. However, the students adjusted to the situation.

The needs of the community were vast and basic, and the students felt that they could make a meaningful contribution with the knowledge they possessed. The empathy and compassion they received from the students were important elements of the success in building relationships, and they had an important role to play in bringing hope to the clients. Clients welcomed them in their homes and valued their presence. However, it was difficult to build a trusting relationship with students if they came on home visits only once or twice.

Cultural differences existed, but were overcome by the understanding and respect the students had for the community. Language is a barrier to both students and organisations when interacting with clients. Clients, on the other hand, felt that the stumbling block could be overcome. Honest human caring and genuine interest bridged this gap.

The organisations felt supported by the students, since they helped them with many tasks. The students performed activities which the organisations normally have no time to carry out.

Communication with the lecturers was mostly effective. Aspects such as being involved in and informed about plans and expectations were important in maintaining a successful relationship between the University and organisations. However, the lecturers need to make more regular contact with the students at the organisations.

All the groups benefited from this deep human experience and gained more than the initial goal envisaged. There is a fine line between the goals of the required experiential learning and meeting the specific needs of the disadvantaged community.

\section{CLOSING REMARK}

The knowledge gained from this research should be ploughed back into education, research and community outreach planning. A system should be developed to assess the value of the services delivered by the students as well as to measure the value it holds for the student.

This project was supported by GUN 2053441: Home-based care for the HIV/AIDS patient in the North West Province, National Research Foundation (Project leader: Prof M Greeff).

\section{BIBLIOGRAPHY}

ASSOCIATION FOR SOUTH AFRICAN SOCIAL WORK EDUCATION INSTITUTIONS (ASASWEI). 2006. Memorandum submitted to the deputy minister for Social Development, titled "Meeting the demand for social workers: realities and challenges in relation to the education of social workers". Pretoria.

BARKER, R.L. 1997. The social work dictionary. Washington: National Association of Social Workers Press. 
BARNETT, T. \& WHITESIDE, A. 2006. AIDS in the twenty-first century: disease and globalisation. New York: Palgrave MacMillan.

BEYTELL, A. 2002. A community-based model for health care social work. Johannesburg: University of Johannesburg. (PhD Thesis)

BEZUIDENHOUT, C. \& JOUBERT, S. 2003. Child and youth misbehaviour in South Africa: a holistic view. Pretoria: Van Schaik Publishers.

BEZUIDENHOUT, F.J. 1998. A reader on selected social issues. Pretoria: Van Schaik Publishers.

BLOOM, M. \& FISCHER, J. 1982. Evaluation practice: guidelines for the accountable professional. Englewood Cliffs: Prentice-Hall, Inc.

BOULTON, M. \& PARKER, M. 2007. Informed consent in a changing environment. Social Science and Medicine, 65(11):2187-2408.

BOZAlEK, V., HENDERSON, N., LAMBERT, W., COLlinS, K. \& GREEN, S. 2007. Social services in Cape Town: an analysis using the political ethics of care. Social Work/Maatskaplike Werk, 43(1):28-40.

CRESWELL, J.W. 2003. Research design: qualitative and quantitative and mixed approaches. London: SAGE Publishers.

DEPARTMENT OF SOCIAL WELFARE. 1998. Social Welfare Action Plan. Available: http://www.welfare.gov.za/documents/doc1998/swap/swap.doc. [Accessed: 05/12/2006].

EVIAN, C. 2003. Primary HIV/AIDS care. Houghton, SA: Jacana Media.

FREDERICK, J. \& GODDARD, C. 2007. Exploring the relationship between poverty, childhood adversity and child abuse from the perspective of adulthood. Child Abuse Review, 16(5):323-341.

GATHIRAM, N. 2005. Poverty alleviation: the need for a knowledgeable, active and empowered civil society. Social Work/Maatskaplike Werk, 41(2):123-130).

GREEFF, M. 2005. Information collection: interviewing. In: DE VOS, A.S., STRYDOM, H., FOUCHÉ, C.B. \& DELPORT, C.S.L. (eds). Research at grass roots: for the social sciences and human service professions. Pretoria: Van Schaik Publishers: 286-313.

KREFTING, L. (ed) 1991. Rigor in qualitative research: the assessment of trustworthiness. American Journal of Occupational Therapy, 45(3):214-221.

LOMBARD, A. 2007. The impact of social welfare policies on social development in South Africa: an NGO perspective. Social Work/Maatskaplike Werk, 43(4):295-316.

MAREE, K. \& PIETERSEN, J. 2007. Sampling. In: MAREE, K. (ed) First steps in research. Pretoria: Van Schaik Publishers: 172-180.

MAY, J. 1998. Poverty and inequality in South Africa. Available: http://www.gov.za/ reports/1998/poverty/index/html. [Accessed: 05/12/2006].

MOUTON, J. \& MARAIS, D.C. 1996. Basic concepts in the methodology of social sciences. Pretoria: RGN Publishers.

NEUMAN, W.L. 2000. Social research methods. Boston: Allyn \& Bacon.

NEW DICTIONARY OF SOCIAL WORK. 1995. Cape Town: Government Printers. 
OKUN, B.F. 1992. Effective helping: interview and counselling techniques. California: Brookes/Cole.

POLIT, D.F. \& HUNGLER, B.P. 1997. Nursing research: principles and methods. Philadelphia: J.B. Lippincot Company.

SCHENCK, C.J. 2004. Problems rural social workers experience. Social Work/Maatskaplike Werk, 40(2):158-171.

SEVEL, J., CUMMINS, L. \& MADRIGAL, C. 1999. Social work skills demonstrated. Boston: Allyn \& Bacon.

SIMPSON, B. 2003. What do residents of informal settlements think social workers should do: voices from Bhambayi. Social Work/Maatskaplike Werk, 39(2):149-160.

SOUTH AFRICA. 1997. The White Paper for the transformation of the Health System of South Africa. Government Gazette, Vol 832. Pretoria: Government Printers.

SOUTH AFRICA. 2007. Budget Speech. Minister of Social Development, Zola Skweyiya, 28 March 2007.

SPIES, M. 2007. The biopsychosocial factors influencing HIV/AIDS patient adherence to antiretroviral therapy (ART): a social work study. Pretoria: University of Pretoria. (DPhil Thesis)

STATISTICS SOUTH AFRICA. 2006. Stats in brief. Available: http:/wwww.statsonline.gov.za/publications/StatsInBrief/StatsInBrief2006.pdf. [Accessed: 05/012/2007].

STRYDOM, M. 2008. Maatskaplike werkers by gesinsorgorganisasies se perspektief op gesinsinstandhoudingsdienste aan hoërisiko-gesinne. Stellenbosch: University of Stellenbosch. (DPhil Thesis)

SWANEPOEL, H. \& DE BEER, F. 2006. Community development: breaking the cycle of poverty. Lansdown, SA: Juta.

TALBOT, L. 1995. Principles and practice of nursing research. St Louis: C.V. Mosby.

TLADI, L.S. 2006. Poverty and HIV/AIDS in South Africa: an empirical contribution. Journal des Aspects Sociaux u VIH/SIDA, 3(1):369-381.

UYS, L. \& CAMERON, S. 2004. Home-based HIV/AIDS care. Cape Town: Oxford University Press.

WONDMIKU, Y., FELEKE, A. \& TAFETE, M. 2005. Successful coupling of community attachment of health science students with relief work for drought victims. Education for Health, 18(2):179-193.

Dr Corinne Strydom, Lecturer, Department of Social Work; Prof Minrie Greeff, Professor in Research, DCur (Psychiatric Nursing); Dr Cornelia Wessels, Senior Lecturer, Department of Social Work; Mrs Engela van der Walt, Senior Lecturer, MCur (Nursing); Prof Paul J Schutte, Director (Communication), Potchefstroom Campus of the North-West University, Potchefstroom, South Africa. 